\title{
Article \\ An Angle-Compensating, Complex-Coefficient PI Controller Used for Decoupling Control of a Permanent-Magnet Synchronous Motor
}

\author{
Jing Guo ${ }^{1,2} \mathbb{D}$, Tao Fan ${ }^{2, *}, \mathrm{Qi}^{2}{ }^{2}$ and Xuhui Wen ${ }^{1,2}$ \\ 1 Advanced Optical Instrument Research Department, University of Chinese Academy of Sciences, \\ Haidian District, Beijing 100049, China; guojing@mail.iee.ac.cn (J.G.); wxh@mail.iee.ac.cn (X.W.) \\ 2 Institute of Electrical Engineering, Chinese Academy of Sciences, Haidian District, Beijing 100190, China; \\ hustliqi@mail.iee.ac.cn \\ * Correspondence: fantao@mail.iee.ac.cn; Tel.: +86-010-82547084
}

check for updates

Citation: Guo, J.; Fan, T.; Li, Q.; Wen,

$X$. An Angle-Compensating, Complex-Coefficient PI Controller Used for Decoupling Control of a Permanent-Magnet Synchronous Motor. Symmetry 2022, 14, 101. https://doi.org/10.3390/ sym14010101

Academic Editors: Liyi Li, Xuzhen Huang and Mingyi Wang

Received: 16 November 2021 Accepted: 20 December 2021 Published: 7 January 2022

Publisher's Note: MDPI stays neutral with regard to jurisdictional claims in published maps and institutional affiliations.

Copyright: () 2022 by the authors. Licensee MDPI, Basel, Switzerland. This article is an open access article distributed under the terms and conditions of the Creative Commons Attribution (CC BY) license (https:// creativecommons.org/licenses/by/ $4.0 /)$.

\begin{abstract}
An asymmetric, cross-coupling effect, as well as digital control delays, in a permanentmagnet synchronous motor (PMSM) will deteriorate its current-control performance in the high-speed range, especially for electric motors used in electric vehicles (EVs) with features such as high-power density and a low carrier/modulation frequency ratio. In this paper, an angle-compensating, complexcoefficient, proportional-integrator (ACCC-PI) controller is proposed, which aims to provide an excellent decoupling performance even with considerable digital control delay. Firstly, the current open and closed loop complex-coefficient transfer functions were established in the synchronous rotation coordinate system. The proposed method, along with existing ones, were then evaluated and theoretically compared. On this basis, the parameter-tuning method of the ACCC-PI controller was presented. Finally, simulation and experimental results proved the correctness of the theoretical analysis and the proposed method.
\end{abstract}

Keywords: asymmetric cross coupling; current-loop control; digital control delay

\section{Introduction}

A permanent-magnet synchronous motor (PMSM) has the advantages of a compact structure, good performance, high efficiency and power density and a wide speed range. It has received a lot of attention in the field of electric vehicles (EVs) [1-5].

In a typical double-loop, control-structure based, field-oriented control (FOC) strategy of a PMSM used as drive motor, the outer loop (speed loop) determines the speed response and the inner loop (current loop) decides the steady and dynamic performance of the whole drive system. Expressed in the synchronous reference frame ( $d q$-frame), the current control loop model is essentially a double-input, double-output (DIDO) system, and asymmetric cross coupling exists between the system of the two orthogonal $d q$-axes, which causes interaction of the currents of the $d q$-axes and induces a slow-current dynamic response [6-9]. In a typical double-loop control structure, the current loop is usually modeled as a symmetric, decoupled $d q$-axis, first-order system [10-12]. Thus, the DIDO system can be seen as two independent single-input, single-output (SISO) systems. However, the decoupled model is not accurate in the case of low carrier ratio. The asymmetric cross coupling is even worse due to the limited current control bandwidth and digital control delay. Normally, in the low-speed operation, the asymmetric coupling is not so significant, and its effect can be regulated without special consideration. However, in the high-speed operation, the asymmetric coupling effect between the $d$-axis and $q$-axis current dynamics becomes so significant that, without proper compensation, the current-control performance leads to instability as the fundamental frequency of the PMSM increases. 
The current control plays a very important role in the PMSM control system. In order to obtain a fast, dynamic response and precise, steady-state control, many methods have been studied, e.g., predictive current control, PI control and hysteresis control [13,14]. State feedback is the most commonly used decoupling method. However, there exists a great dependence on the accuracy of the motor parameters. In [15], an improved currentdecoupling controller was designed, and parameters were detected online based on the model reference-adaptive method. Feed-forward and closed-loop feedback were added to the detection system to ensure the accuracy and robustness of parameter detection, but the influence of digital control delay on the current loop was not considered. In [16], a dynamic decoupling control algorithm, using fuzzy controllers (FCs) and a neural network identifier (NNI), was proposed. Zhou compared the expressions and settings of real-coefficient and complex-coefficient PI controllers. Based on the experimental results, the advantages and disadvantages of the two PI regulators were compared in terms of decoupling of the control structure, the dynamic response speed of the current loop and parameter robustness [17]. The work of [18-20] analyzed the influence of digital control delay on system stability, and adopted the methods of double update and double sampling, along with deadbeat control to compensate it.

In this paper, current-loop control was analyzed along with complex-coefficient transfer functions, which could fully characterize the asymmetric cross coupling of the current loop and convert a DIDO system into a SISO form. Moreover, some useful methods used to analyze SISO systems, such as root locus, can be used to analyze the influence of the impedance coupling term of a PMSM and the delay angle on the stability of the currentcontrol loop. Then, an alternative decoupling method based on a complex-coefficient, proportional-integrator (CC-PI) controller was proposed, which could prevent the current loop from being unstable in the case of low carrier ratio. On this basis, the parameter tuning method of an ACCC-PI controller was presented.

The rest of the paper is organized as follows. Section 2 presents the current openand closed-loop, complex-coefficient transfer functions. Section 3 analyses two traditional decoupling methods and presents the proposed method. Section 4 provides the simulation and experimental results. Section 5 discusses the results of Section 4 . Finally, Section 6 concludes the work and presents future work.

\section{Current-Loop Modeling}

\subsection{Modeling of a PMSM}

The typical model of a PMSM in a synchronous rotating frame is illustrated in Figure 1a. The voltage equations of a PMSM based on the extended EMF Eex can be expressed in matrix form, as designated in Equation (1) [21,22].

$$
\left[\begin{array}{l}
u_{d} \\
u_{q}
\end{array}\right]=\left[\begin{array}{cc}
R_{s}+L_{d} s & -\omega_{e} L_{q} \\
\omega_{e} L_{q} & R_{s}+L_{d} s
\end{array}\right] \times\left[\begin{array}{c}
i_{d} \\
i_{q}
\end{array}\right]+\left[\begin{array}{c}
0 \\
E_{e x}
\end{array}\right]
$$

where,

$$
E_{e x}=\left(L_{d}-L_{q}\right)\left(\omega_{e} i_{d}-s i_{q}\right)+\omega_{e} \cdot \psi_{f}
$$

$R_{s}$ represents the stator resistance; $\psi_{f}$ represents the permanent-magnet flux linkage; $\omega_{e}$ represents the synchronous angular velocity; $u_{d}$ and $u_{q}$ represent the $d$ - and $q$-axis voltage; $i_{d}$ and $i_{q}$ represent the $d$ - and $q$-axis current; $L_{d}$ and $L_{q}$ represent the $d$ - and $q$-axis inductance of the PMSM, respectively.

Equation (3) can be calculated from Equation (1).

$$
\left[\begin{array}{l}
i_{d} \\
i_{q}
\end{array}\right]=\left[\begin{array}{cc}
Z_{d d}^{-1} & Z_{d q}^{-1} \\
Z_{q d}^{-1} & Z_{q q}^{-1}
\end{array}\right] \cdot\left[\begin{array}{c}
u_{d} \\
u_{q}^{\prime}
\end{array}\right]
$$


where,

$$
\left\{\begin{array}{c}
Z_{d d}^{-1}=\left(L_{q} s+R_{s}\right) / R \\
Z_{d q}^{-1}=L_{q} \omega_{e} / R \\
Z_{q d}^{-1}=-L_{d} \omega_{e} / R \\
Z_{q q}^{-1}=\left(L_{d} s+R_{s}\right) / R \\
R=L_{d} L_{q} s^{2}+\left(L_{d}+L_{q}\right) R_{s} s+L_{d} L_{q} \omega_{e}^{2}+R_{s}^{2} \\
u_{q}^{\prime}=u_{q}-\omega_{e} \psi_{f}
\end{array}\right.
$$

According to Equation (3), the impedance-coupling model of a PMSM is illustrated in Figure $1 b$.

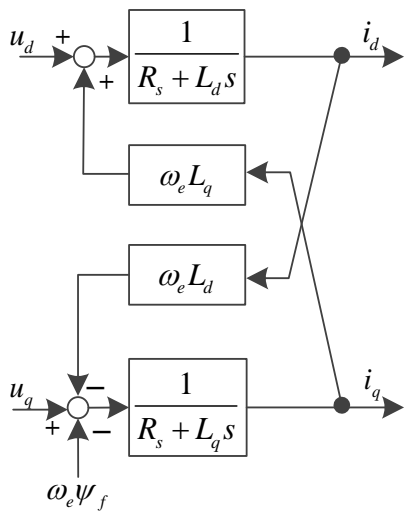

(a)

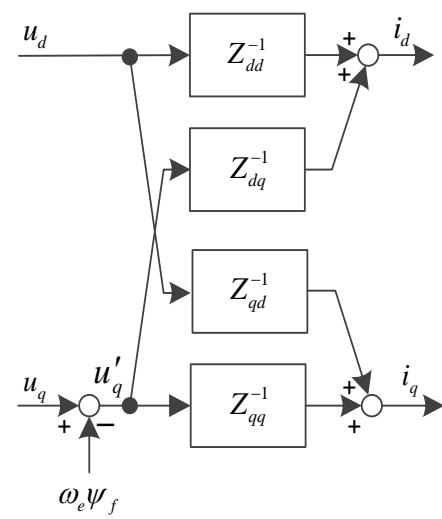

(b)

Figure 1. Model of a PMSM. (a) traditional PMSM model; (b) impedance-coupling model of a PMSM based on the extended EMF.

\subsection{Modeling of Digital Delays}

In Figure $2, \vec{U}_{s}$ represents the voltage vector; $\vec{E}_{0}$ represents the EMF vector; $\vec{I}_{d}$ and $\vec{I}_{q}$ represent the $d$ - and $q$-axis current vector, respectively. Non-negligible digital control delay existed due to the digital computation and pulse width modulation. The angle between the ideal direct axis $\mathrm{d}$ and the actual direct axis $\mathrm{d}^{\prime}$ is denoted by Equation (5).

$$
\theta_{d}=k \omega_{e} T_{s}=2 \pi k\left(f_{e} / f_{s}\right)=2 \pi k\left(1 / f_{\text {ratio }}\right)
$$

where $k$ represents the delay coefficient; $T_{s}$ represents the control period; $f_{e}$ represents the electric frequency; $f_{s}$ represents the switching frequency; $f_{\text {ratio }}$ represents the control carrier ratio.

In the ideal situation, the components of the $d q$-axes $\vec{U}_{d}$ and $\vec{U}_{q}$ of the voltage vector $\vec{U}_{s}$ are obtained, as designated in Equation (6).

$$
\left|\vec{U}_{d}\right|=\left|\vec{U}_{s}\right| \sin \theta \quad\left|\vec{U}_{q}\right|=\left|\vec{U}_{s}\right| \cos \theta
$$

where $\theta$ represents the angle between the voltage vector $\vec{U}_{s}$ and the $q$ axis, as shown in Figure 2. Considering the digital control angle delay, the actual $d^{\prime} q^{\prime}$ axes' components $\vec{U}_{d}^{\prime}$ and ${\overrightarrow{U^{\prime}}}_{q}$ of the voltage vector $\vec{U}_{s}$ are illustrated in Equation (7).

$$
\left\{\begin{array}{l}
\mid \vec{U}_{d}^{\prime} \\
\vec{U}_{q}^{\prime}
\end{array}|=| \begin{array}{l}
\vec{U}_{s} \\
\vec{U}_{s}
\end{array}\left|\sin \left(\theta_{d}-\theta\right)=\right| \begin{array}{l}
\vec{U}_{s} \\
\cos \left(\theta_{d}-\theta\right)=\left|\begin{array}{l}
\left(\sin \theta_{d} \cos \theta-\cos \theta_{d} \sin \theta\right) \\
\vec{U}_{s}
\end{array}\right|\left(\cos \theta_{d} \cos \theta+\sin \theta_{d} \sin \theta\right)
\end{array}\right.
$$




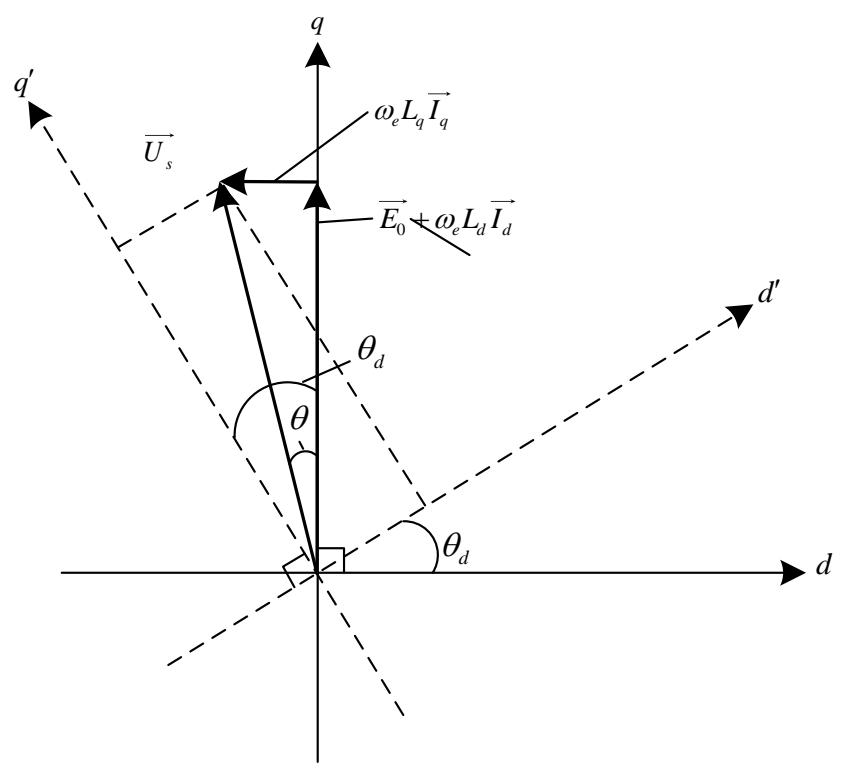

Figure 2. Modeling of angle delay in the synchronous reference frame.

According to Equation (7) and Figure 1b, the current-loop control block diagram with the digital control delays of the PMSM is shown in Figure $3, i_{d}^{*}$ and $i_{q}^{*}$ represent the $d$ - and $q$-axis command current, respectively. The angle delay had a similar coupling structure to the asymmetric PMSM coupling model.

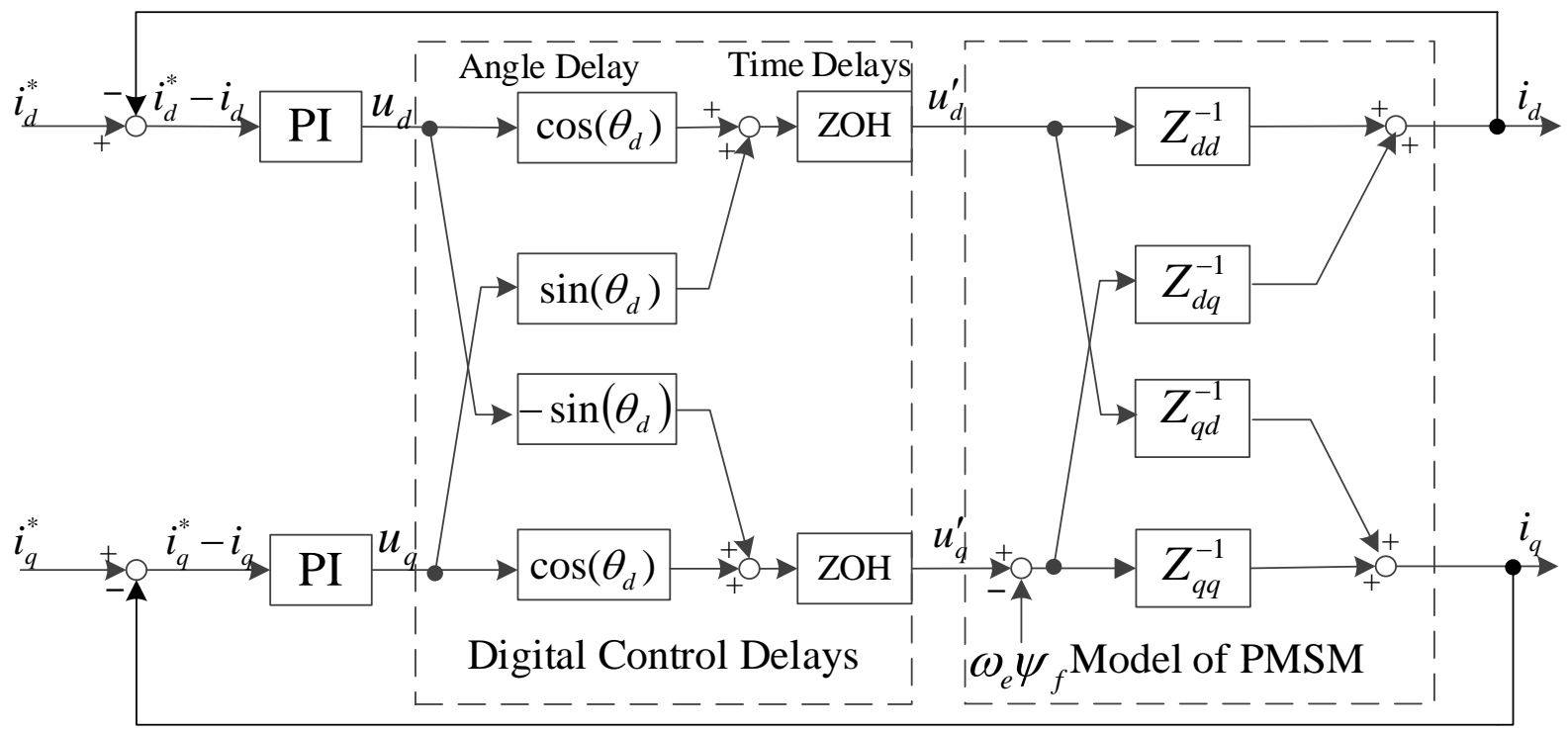

Figure 3. Current-loop control block diagram with digital control delays of the PMSM.

Due to the limited current-control bandwidth and control delay, the asymmetric cross-coupling effect became worse.

\subsection{Complex-Coefficient Transfer Functions of the Current Loop}

In the case of the same PI parameters, the current-loop-control model expressed by the complex-coefficient transfer functions is shown in Figure 4, where $\vec{Z}=R_{s}+L s+\mathrm{j} \omega_{e} L$; $\overrightarrow{u_{d q}}=u_{d}+\mathrm{j} u_{q} ; \overrightarrow{u_{d^{\prime} q^{\prime}}}=u_{d^{\prime}}+\mathrm{j} u_{q^{\prime}} ; \vec{i}_{d q}=i_{d}+\mathrm{j} i_{q} ; \overrightarrow{i_{d q}^{*}}=i_{d}^{*}+\mathrm{j} i_{q}^{*} ; G_{\mathrm{PI}}(s)=k_{p}\left(1+k_{i} / s\right)$ and $\mathrm{j}$ represents the complex sign. 


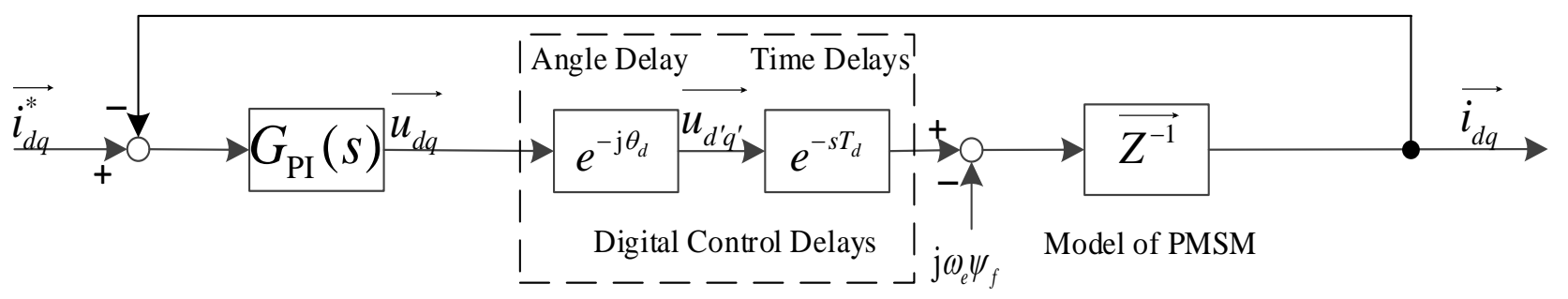

Figure 4. Current-loop model expressed by complex-coefficient transfer functions.

\section{Proposed Angle-Compensating, Complex-Coefficient PI Controller}

\subsection{Traditional Decoupling Method}

The current feedback (CFB) [17] and complex-coefficient PI (CC-PI) [19] are the most commonly applied decoupling methods. Figure 5 shows the block diagram of the two decoupling methods.

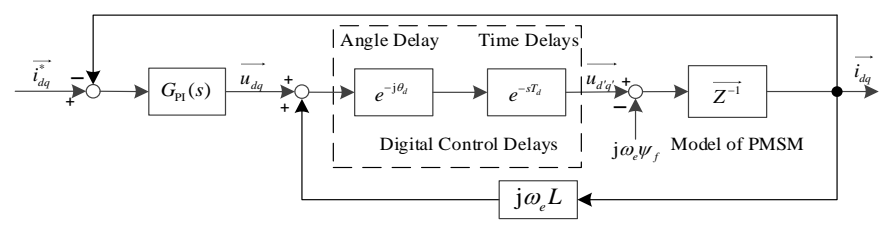

(a)

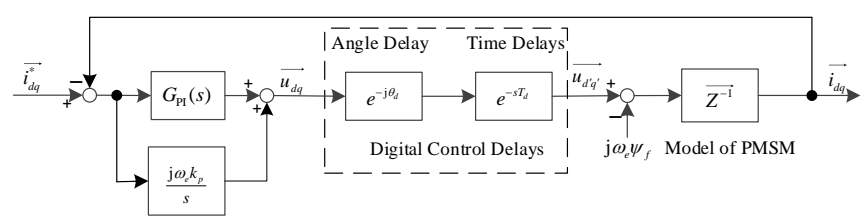

(b)

Figure 5. Block diagram of the traditional decoupling algorithm. (a) CFB; (b) CC-PI.

In general, $\omega_{n}<<1 / T_{d}$ and the current open- and closed-loop, complex-coefficient transfer functions can be simplified as designated in Equations (8) and (9).

$$
\begin{gathered}
G_{o}(s)=\omega_{b} \frac{\left(s+\omega_{n}\right) e^{-\mathrm{j} \theta_{d}}}{s\left(s+\omega_{n}+\mathrm{j} \omega_{e}\right)\left(T_{d} s+1\right)} \approx \omega_{b} \frac{\left(s+\omega_{n}\right) e^{-\mathrm{j} \theta_{d}}}{s\left(s+\omega_{n}+\mathrm{j} \omega_{e}\right)} \\
G_{c}(s)=\frac{G_{o}(s)}{1+G_{o}(s)} \approx \frac{\omega_{b}\left(s+\omega_{n}\right) e^{-\mathrm{j} \theta_{d}}}{s^{2}+\left(\omega_{b} e^{-\mathrm{j} \theta_{d}}+\omega_{n}+\mathrm{j} \omega_{e}\right) s+\omega_{b} \omega_{n} e^{-\mathrm{j} \theta_{d}}}
\end{gathered}
$$

According to Figure 5, the current closed-loop, complex-coefficient transfer functions, with a decoupling method, can be deduced as designated in Equations (10) and (11).

$$
\begin{gathered}
G_{C_{-} \mathrm{CFB}}(s)=\frac{\omega_{b}\left(s+\omega_{n}\right) e^{-\mathrm{j} \theta_{d}}}{s\left(s+\omega_{n}+\mathrm{j} \omega_{e}-\mathrm{j} \omega_{e} e^{-\mathrm{j} \theta_{d}}\right)+\omega_{b}\left(s+\omega_{n}\right) e^{-\mathrm{j} \theta_{d}}} \\
G_{C_{-} \text {CCPI }}(s)=\frac{\omega_{b} e^{-\mathrm{j} \theta_{d}}}{s+\omega_{b} e^{-\mathrm{j} \theta_{d}}}
\end{gathered}
$$

By comparing Equations (10) and (11), both decoupling methods could decouple the current loop as a first-order inertial link with $\theta_{d}=0$ rad. However, the CC-PI decoupling method had a simpler closed-loop transfer expression when a digital delay was added. The closed-loop poles can be expressed using Equation (12).

$$
s=-\omega_{b} \cdot \cos \left(\theta_{d}\right)+\mathrm{j} \omega_{b} \cdot \sin \left(\theta_{d}\right)
$$

The pole in the right half plane appeared only when the delay angle $\theta_{d}>\pi / 2 \mathrm{rad}$, which meant the current loop became unstable.

On the contrary, the closed-loop pole expression of the CFB decoupling method was very complicated and more parameter-sensitive. The performance of the two decoupling methods with angle delay was compared through simulation in Section 4.1. 


\subsection{Proposed ACCC-PI Controller}

The structure of the proposed ACCC-PI decoupling current controller is shown in the shadow box outlined with a dotted line in Figure 6, which had the mixed structure of direct PI controllers, the cross-coupling integral controllers and the angle-compensating part.

The complex-coefficient transfer function of the ACCC-PI controller was obtained as designated in Equation (13).

$$
G_{\text {ACCC-PI }}(s)=G_{r}(s)+\mathrm{j} G_{i}(s)
$$

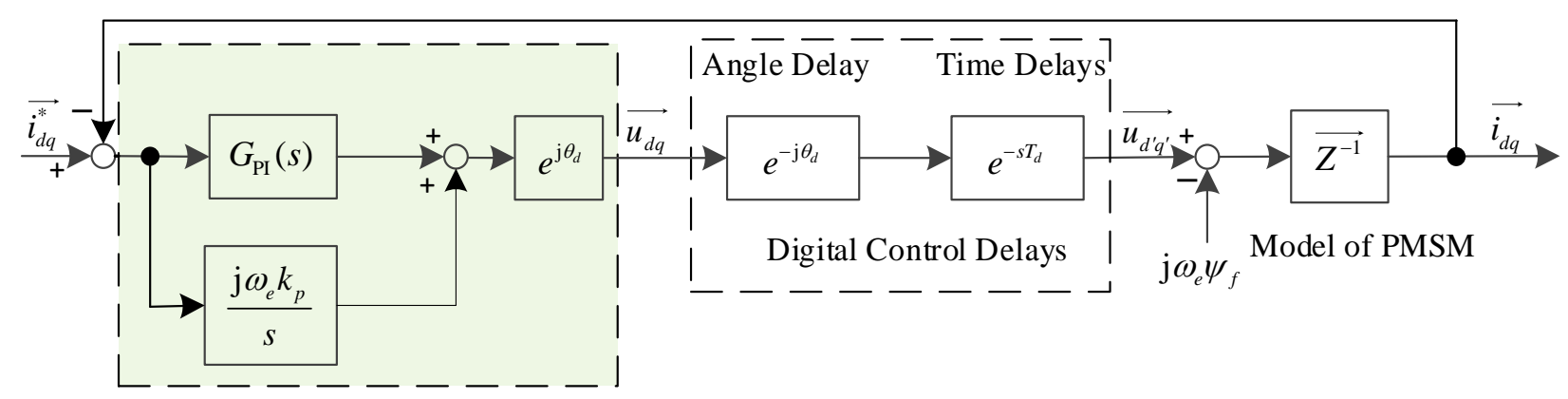

Figure 6. Block diagram of current-loop control with the ACCC-PI controller.

Figure 7 shows the current-loop control block diagram with the proposed ACCC-PI controller. Symbol "^" represents the estimated value. Where,

$$
\left\{\begin{aligned}
G_{\mathrm{rd}}(s)= & k_{p d} \cos \hat{\theta}_{d}+\frac{k_{p d} k_{i d} \cos \hat{\theta}_{d}-k_{p d} \omega_{\mathrm{e}} \sin \hat{\theta}_{d}}{s} \\
G_{\mathrm{id}}(s)= & k_{p q} \sin \hat{\theta}_{d}+\frac{k_{p q} k_{i q} \sin \hat{\theta}_{d}+k_{p q} \omega_{\mathrm{e}} \cos \hat{\theta}_{d}}{G_{\mathrm{rq}}(s)=} k_{p q} \cos \hat{\theta}_{d}+\frac{k_{p q} k_{i q} \cos \hat{\theta}_{d}-k_{p q} \omega_{\mathrm{e}} \sin \hat{\theta}_{d}}{G_{\mathrm{iq}}(s)=} k_{p d} \sin \hat{\theta}_{d}+\frac{k_{p d} k_{i d} \sin \hat{\theta}_{d}+k_{p d} \omega_{\mathrm{e}} \cos \hat{\theta}_{d}}{k_{p d}=\hat{L}_{d} \omega_{b} ; k_{i d}=\hat{R}_{s} / \hat{L}_{d}} \\
& k_{p q}=\hat{L}_{q} \omega_{b} ; k_{i q}=\hat{R}_{s} / \hat{L}_{q}
\end{aligned}\right.
$$

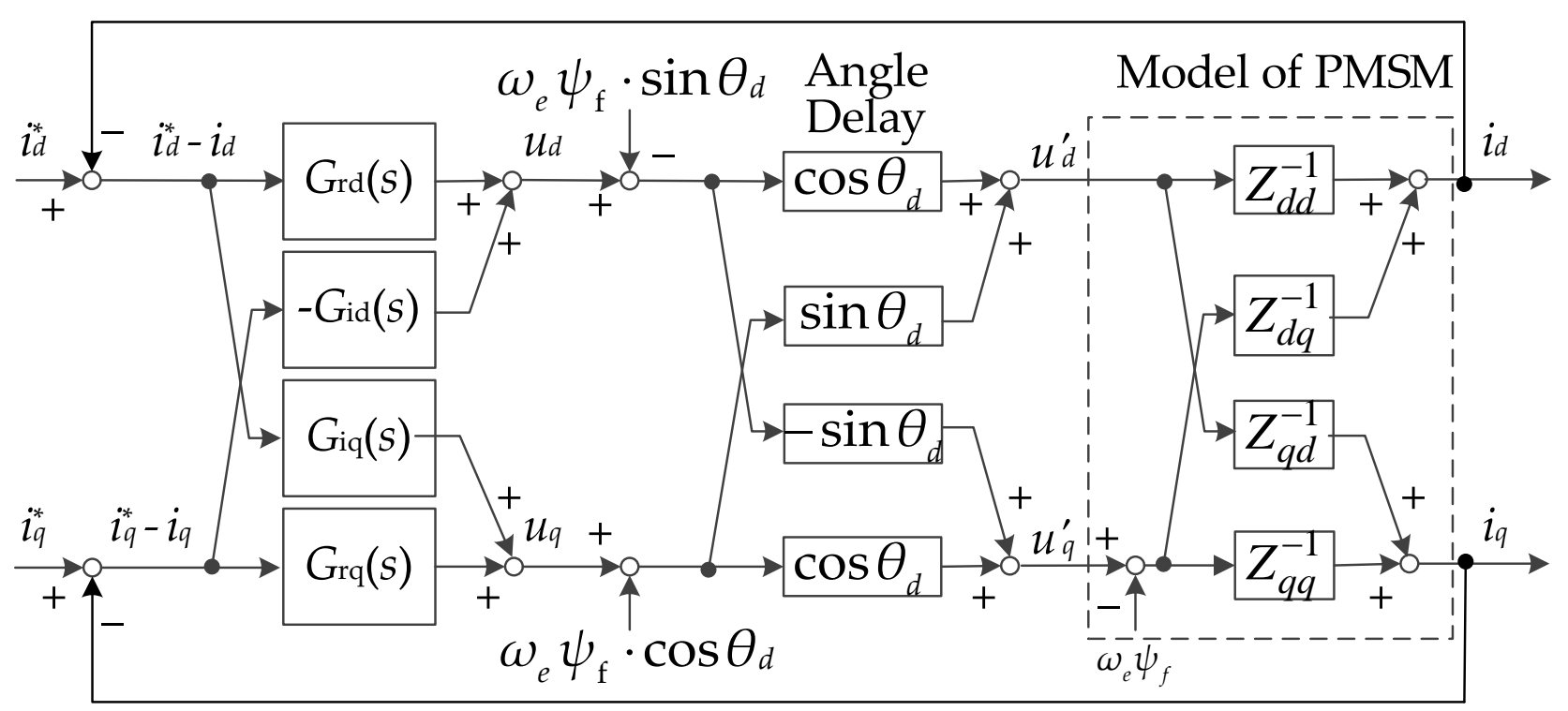

Figure 7. Current-loop control block diagram with the ACCC-PI controller.

If $\hat{\theta}_{d}=\theta_{d}, \hat{\psi}_{\mathrm{f}}=\psi_{\mathrm{f}}$, the control block diagram of the current loop of the permanentmagnet synchronous motor is illustrated in Figures 8 and 9. 


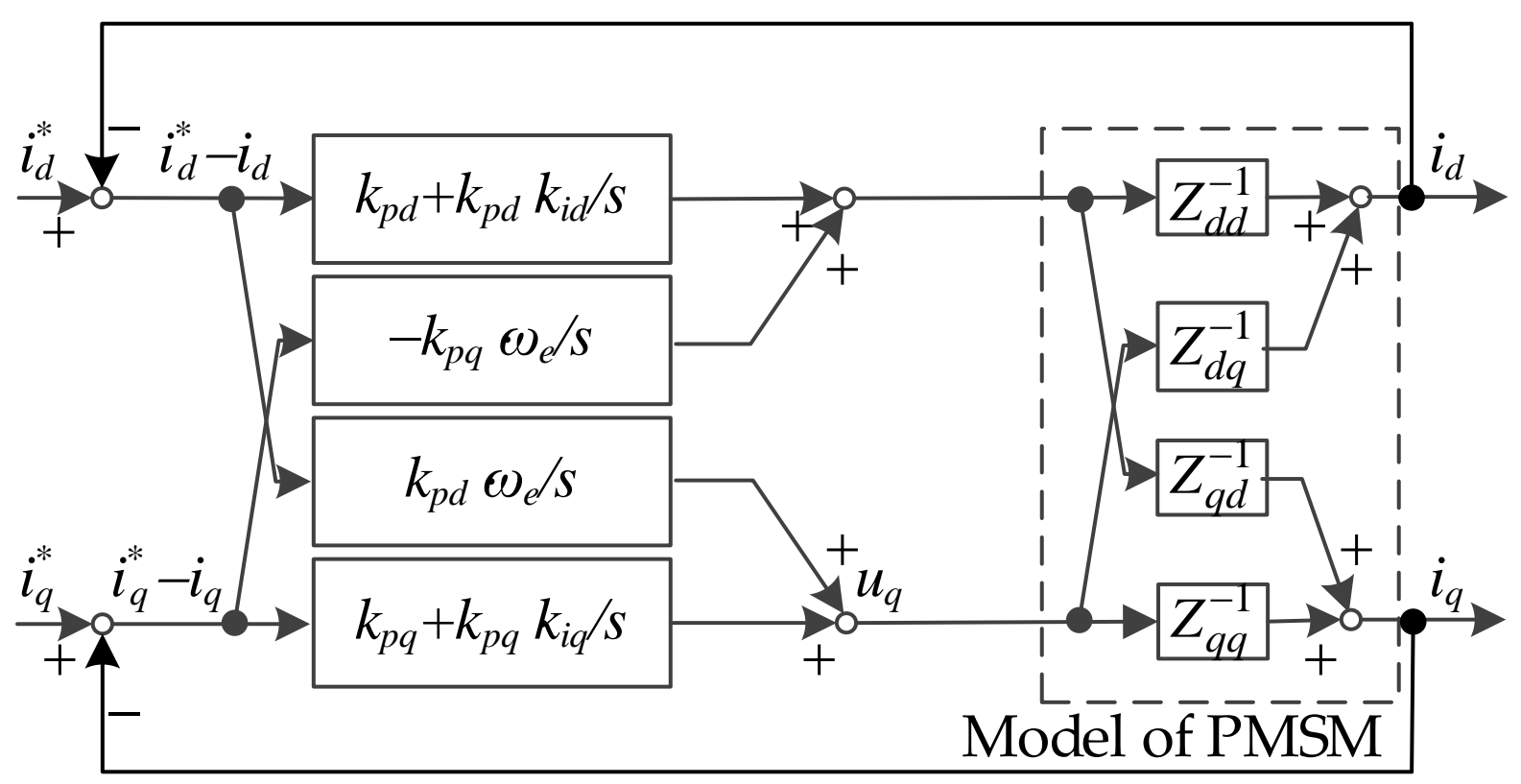

Figure 8. Block diagram of the current loop with correct delay angle and permanent-magnet flux.
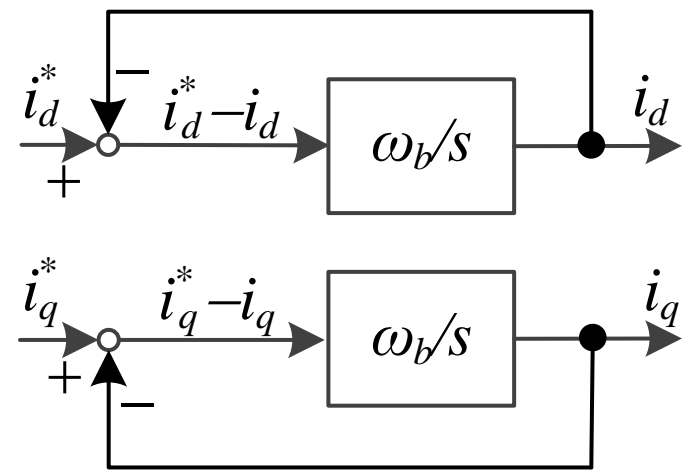

Figure 9. Block diagram of the current loop with correct delay angle and constant motor parameters.

If $\hat{L}_{d}=L_{d} ; \hat{L}_{q}=L_{q} ; \hat{R}_{s}=R_{s}$, after the adoption of the proposed ACCC-PI controller, the current closed-loop complex-coefficient transfer function is illustrated in Equation (15).

$$
G_{C_{-} A C C C P I}(S)=\omega_{b} /\left(s+\omega_{b}\right)
$$

According to Equation (15), the current loop had a negative, real-part closed pole $\left(-\omega_{b}, 0\right)$, and the performance of the current loop was only related to the control bandwidth.

\section{Simulations and Experiments}

The simulations and experiments were built according to the parameters of the PMSM in Table 1. Figure 10 shows the control block diagram used in the experiment. The control algorithm was realized through a 32-bit processor TMS320F28335, and the inverter stack was made of a drive module designed for hybrid- and electric vehicle applications (FS820R08A6P2B). We used the PMSM with parameters listed in Table 1 and set the experimental conditions to be the same as those of the simulation. Figures 11 and 12 shows the experiment platform. 
Table 1. Parameters of the PMSM.

\begin{tabular}{cc}
\hline Parameters & Value \\
\hline Pole pairs & 6 \\
Phase resistance & $8[\mathrm{~m} \Omega]$ \\
$d$-axis inductance & $0.16[\mathrm{mH}]$ \\
$q$-axis inductance & $0.16[\mathrm{mH}]$ \\
Permanent-magnet flux linkage & $0.0488[\mathrm{~Wb}]$ \\
\hline
\end{tabular}

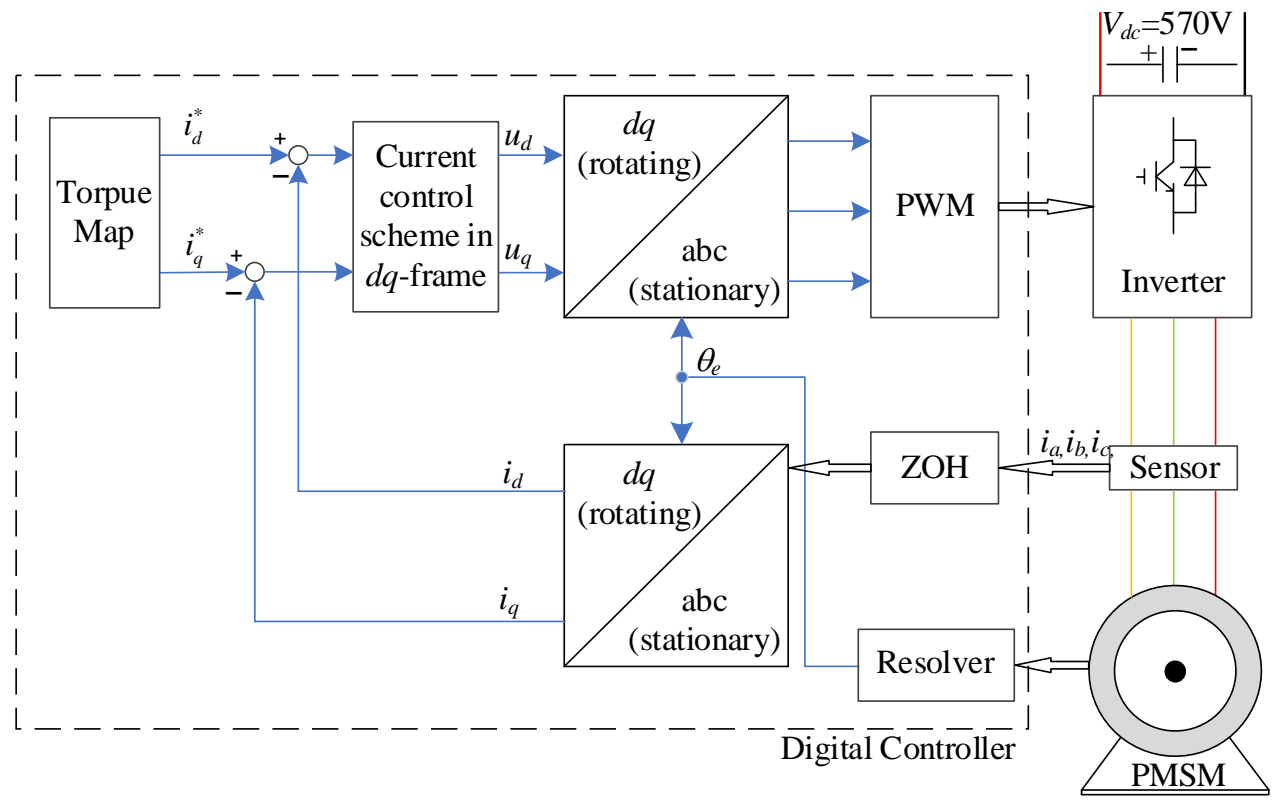

Figure 10. Control block diagram used in the experiment.

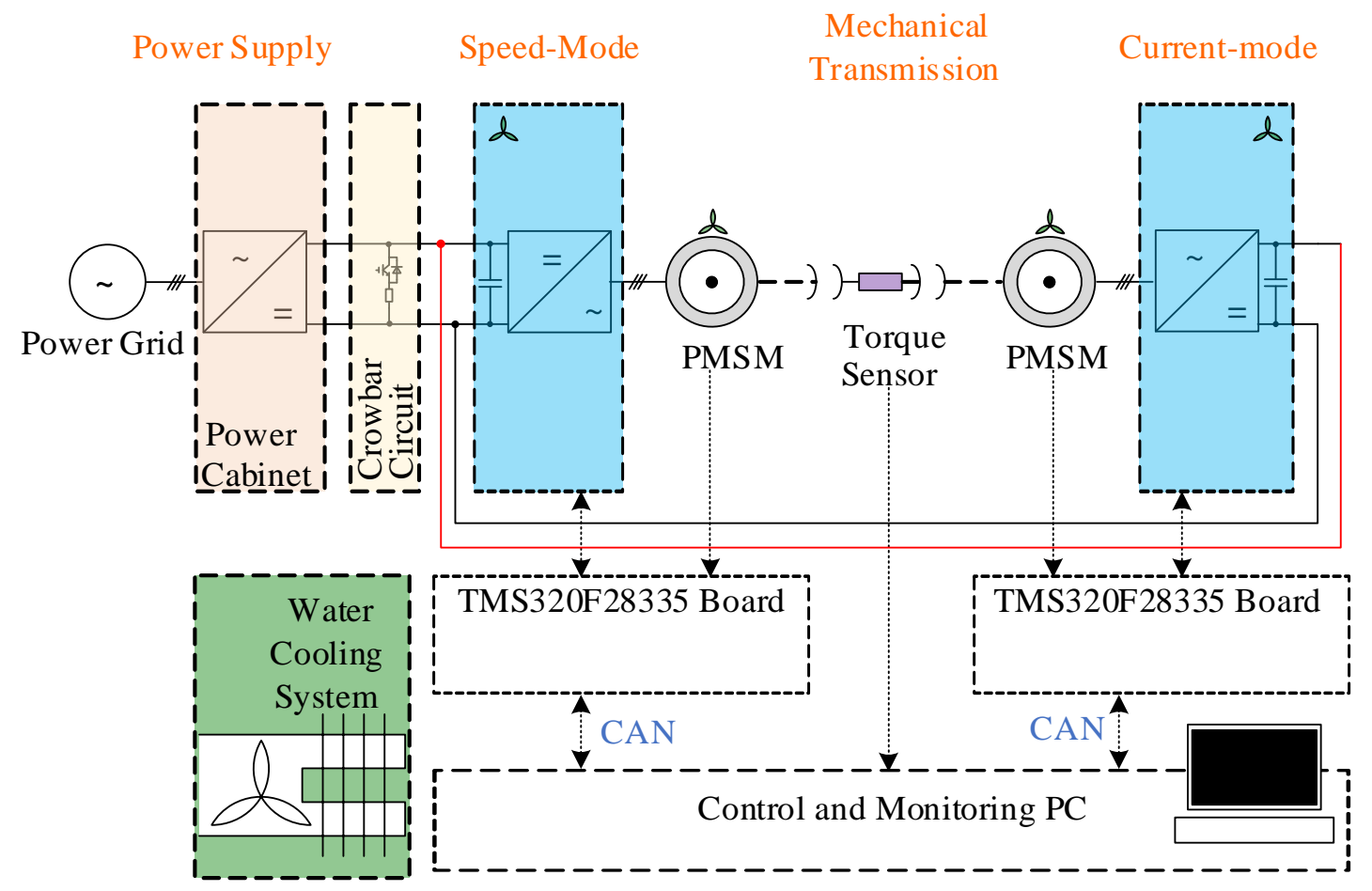

Figure 11. Block diagram of the experiment. 


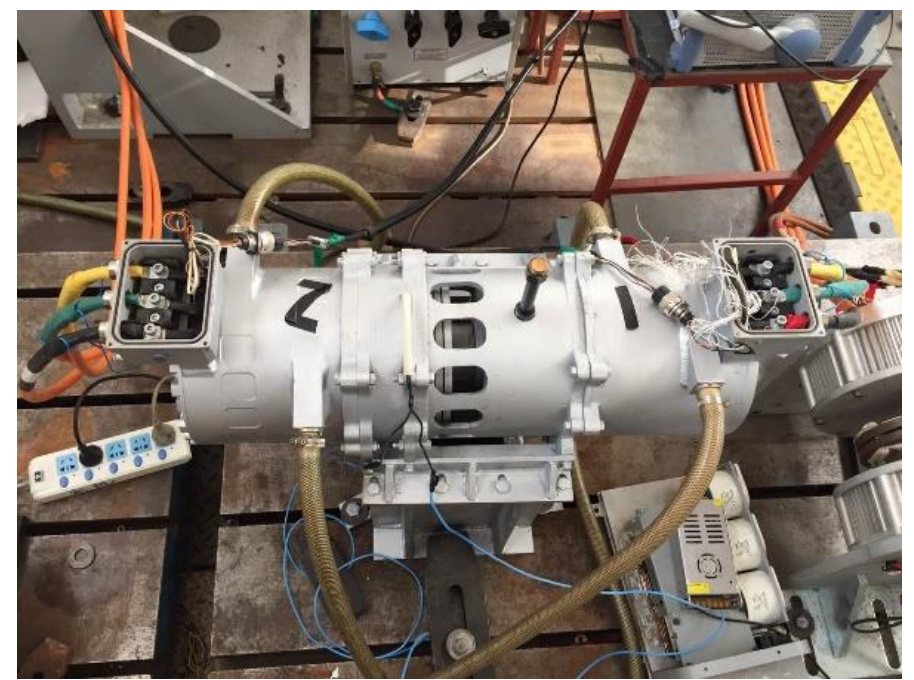

Figure 12. Back-to-back test platform.

\subsection{Simulations of Different Decoupling Algorithms}

The simulated $d q$-axes' current response without a decoupling algorithm is illustrated in Figure 13, the cross coupling of the current-control loop was aggravated and the dynamic response became negatively affected by the motor impedance coupling (MIC) and digital control angle delay (AD).

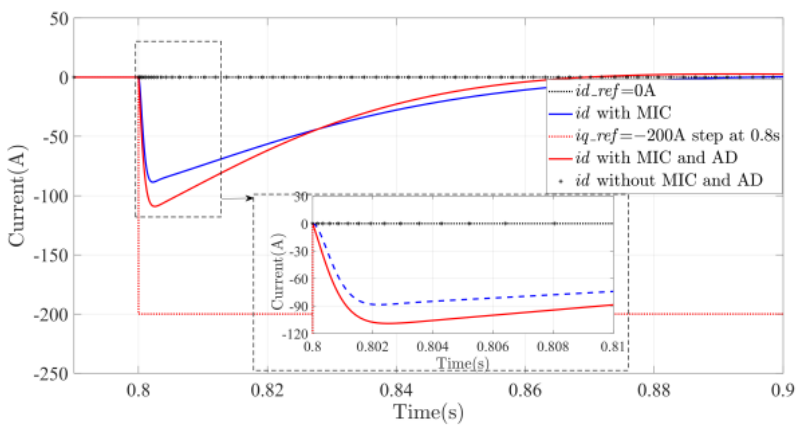

(a)

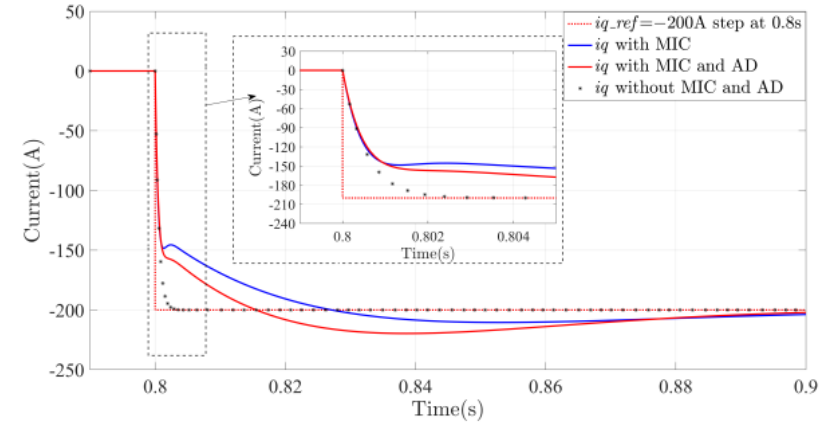

(b)

Figure 13. Simulation waveform of $d q$-axes' current response affected by the motor impedance coupling (MIC) term and digital control angle delay term, the PI parameters of the current-control loop were $(\mathrm{kp}=0.3, \mathrm{ki}=50)$ and the rotor electrical angular velocity $\omega_{e}$ was $1256 \mathrm{rad} / \mathrm{s}$. (a) $d$-axis current response; (b) $q$-axis current response.

The performance of the three decoupling methods was compared through simulation in the same conditions, as shown in Figure 14.

At the beginning of the simulation, the current command of the $d$-and $q$-axis were all zero, and the $-200 \mathrm{~A}$ current step command of the $q$ axis occurred at $0.8 \mathrm{~s}$. The decoupling and dynamic performance of the algorithm were evaluated by observing the current response of $d$ - and $q$-axis. As shown in Figure 14a, according to Equations (13) and (14), the CFB and CC-PI methods had the same decoupling effect without considering the digital control delay angle, that is, there was no fluctuation in the $d$-axis current and there was the same dynamic performance of the $q$-axis current. However, when the digital control delay angle was takeninto account in Figure 14b, the CC-PI decoupling method had better dynamic response characteristics than the CFB decoupling method under the same simulation conditions, but still had a coupling current in the $d$-axis. The coupling $d$-axis current disappeared when the proposed ACCC-PI controller was used. 


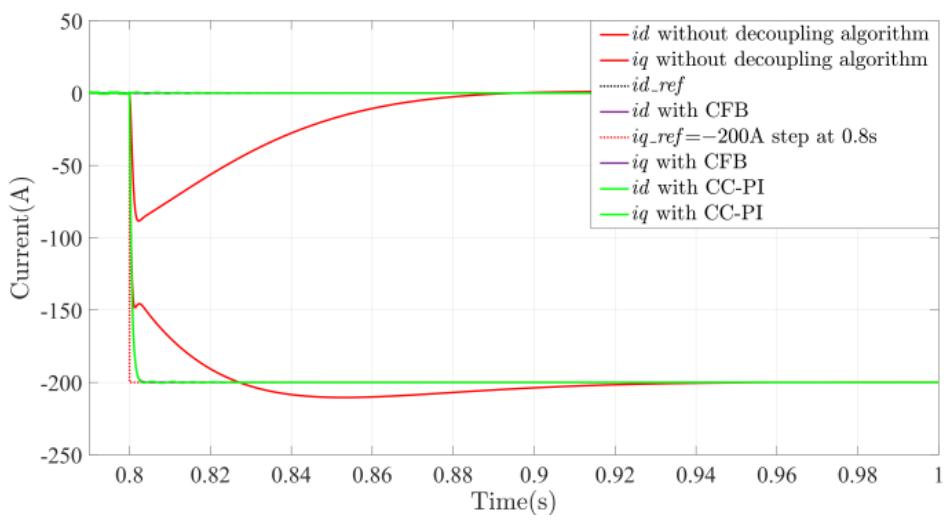

(a)

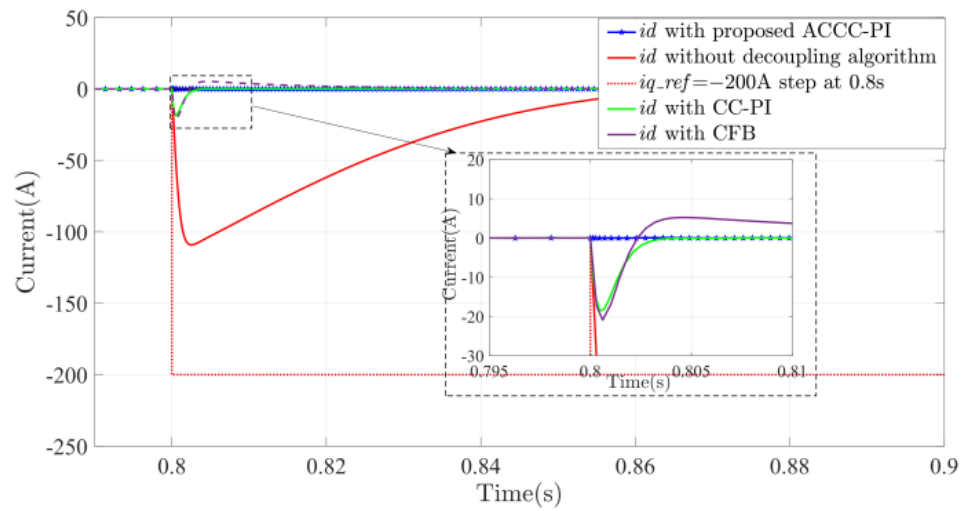

(b)

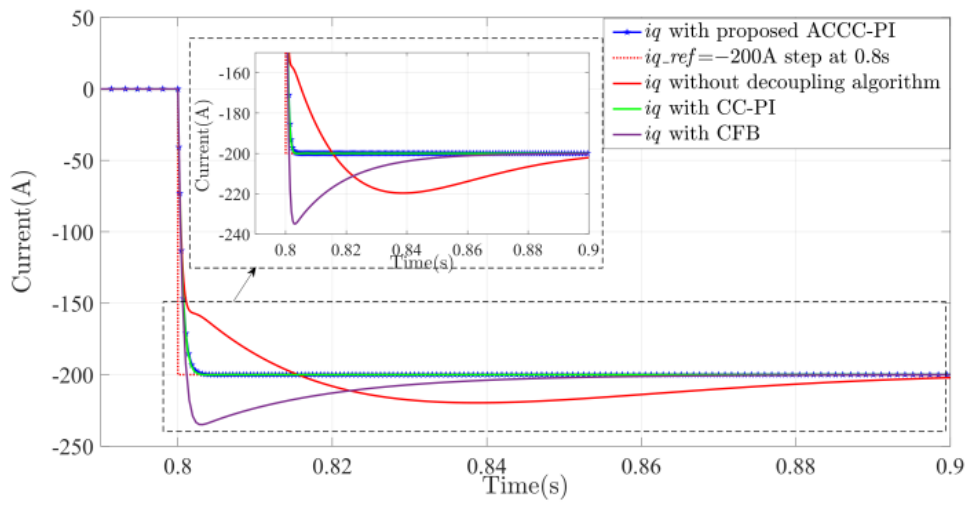

(c)

Figure 14. $d q$-axes' current-response simulation waveform using different decoupling algorithms, the PI parameters of the current-control loop were $(\mathrm{kp}=0.3, \mathrm{ki}=50)$, rotor electrical angular velocity $\omega_{e}$ was $1256 \mathrm{rad} / \mathrm{s}$. (a) $d q$-current response using the CFB and CCPI decoupling methods, regardless of the angle delay; (b) $d$-axis current response with angle delay; (c) $q$-axis current response with angle delay.

\subsection{Experiments of Different Decoupling Algorithms}

The proposed method of ACCC-PI was experimentally verified by the back-to-back test platform as shown in Figure 12. The performance of the three decoupling methods were compared through the phase current in Figure 15a and $d q$-axes' current responses in Figure 15b,c. The PI parameters of the current-control loop were $(\mathrm{kp}=0.3, \mathrm{ki}=50)$, corresponding control bandwidth was $1571 \mathrm{rad} / \mathrm{s}$ and the motor speed was $2000 \mathrm{rpm}$. 


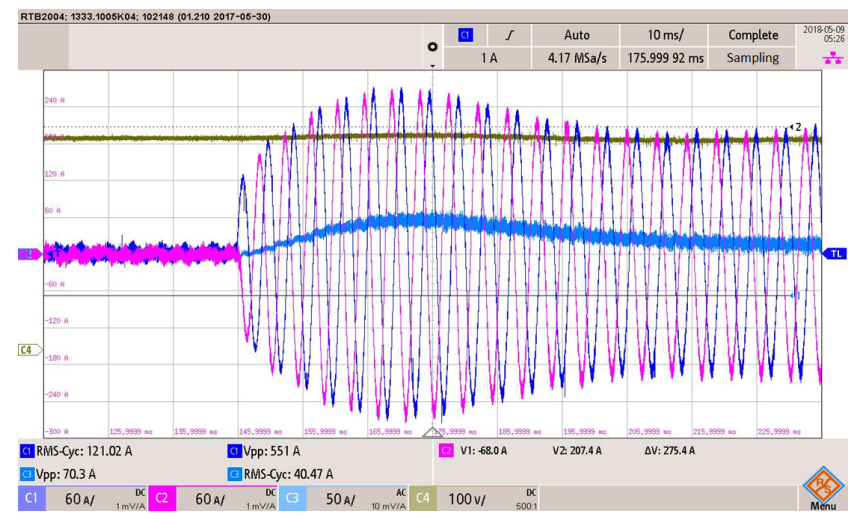

(without decoupling algorithm)

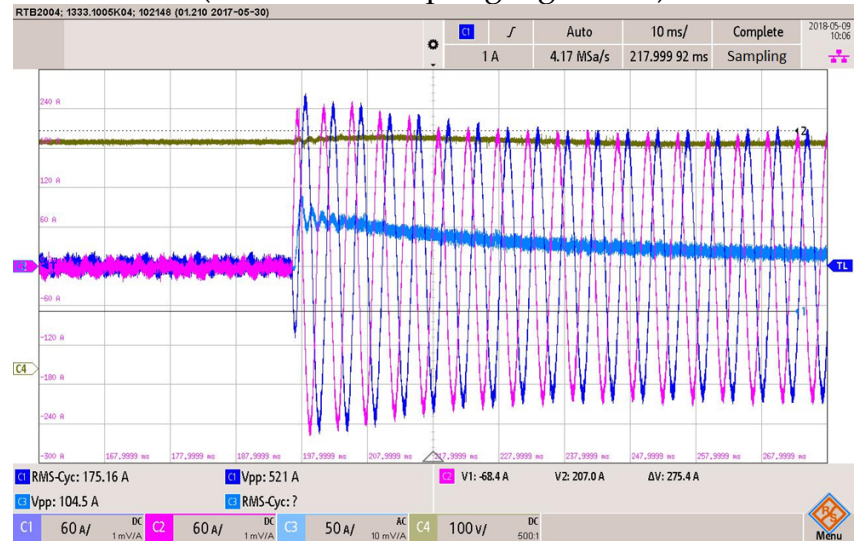

(CFB)

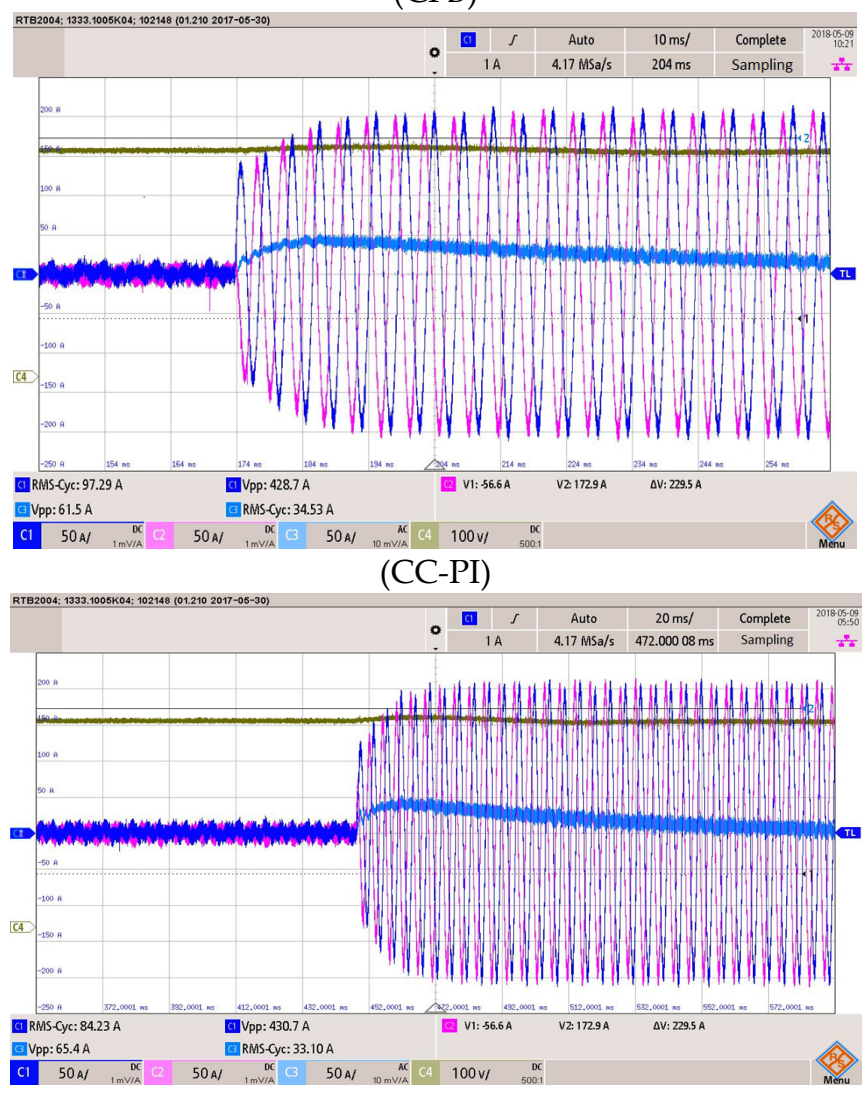

(ACCC-PI)

(a)

Figure 15. Cont. 


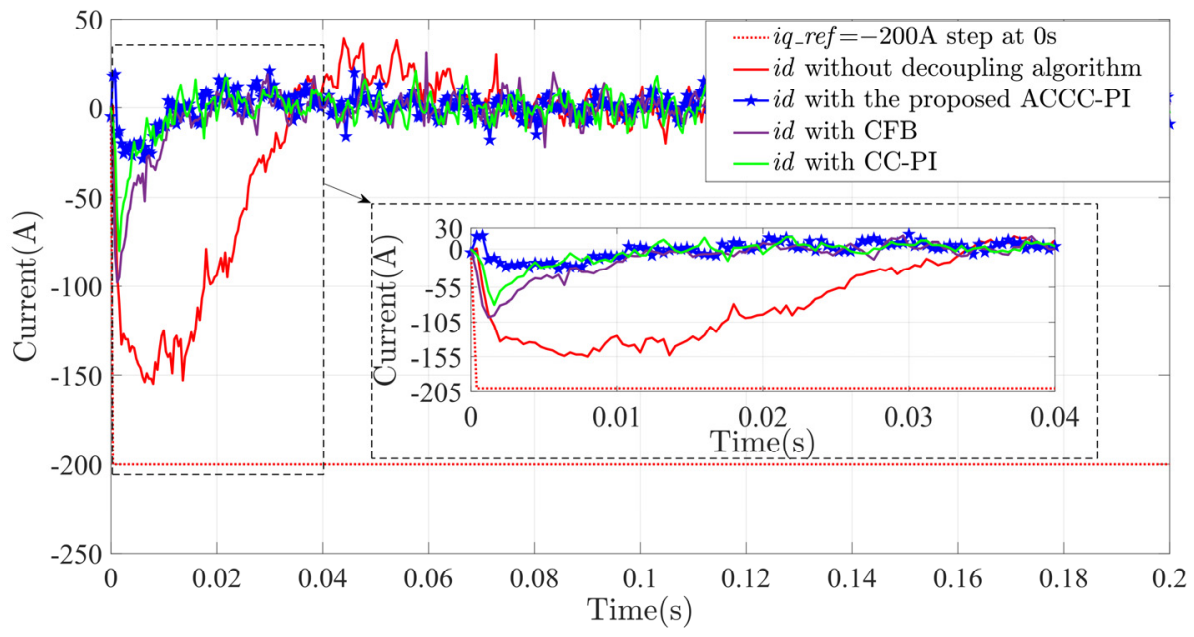

(b)

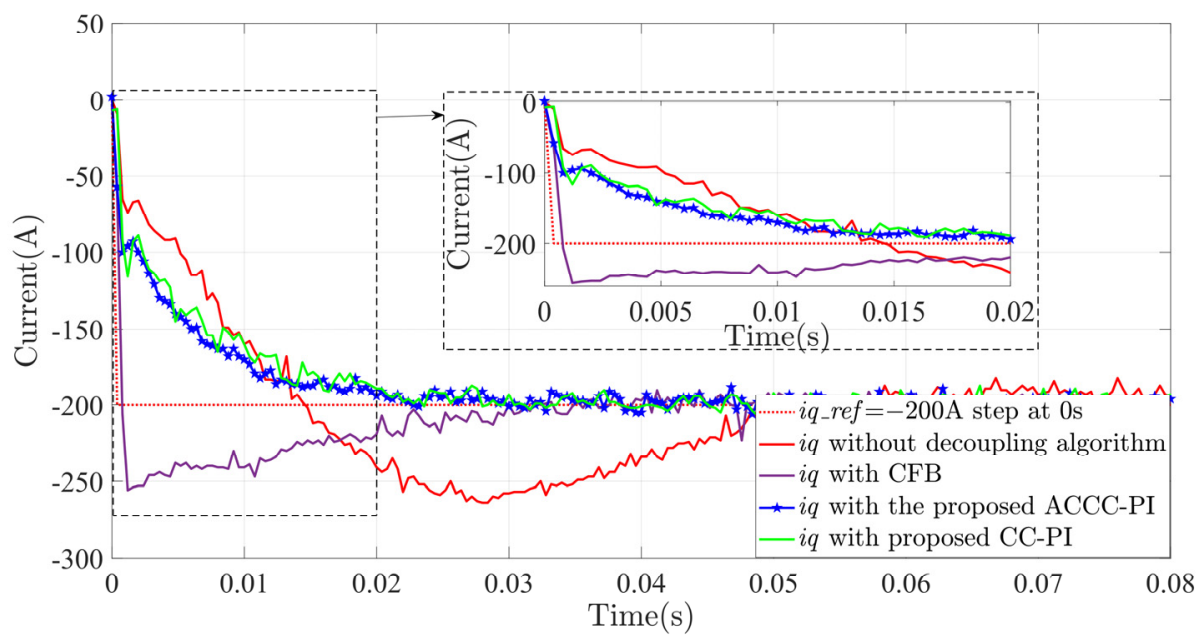

(c)

Figure 15. Comparison of current response using different algorithms under the q-axis currentcommand step. (a) Phase current waveform; (b) $d$-axis current response; (c) $q$-axis current response.

The experimental results were basically consistent with the theoretical and simulation results, the proposed ACCC-PI controller had the best dynamic performance and decoupling effects. As shown in Figure 15b,c, when the -200A step occurred in the $q$-axis current command, the CC-PI decoupling method had better $q$-axis current dynamic response than the CFB decoupling method (same as the simulation results in Figure 14c), but still had a coupling current in the $d$-axis (about -100A). However, the proposed ACCC-PI decoupling method had the smallest coupling $d$-axis current $(-25 \mathrm{~A})$ and the best $q$-axis current dynamic performance (with non-overshoot and fast response).

\section{Discussion}

In order to reduce the weight and volume of the PMSM drive system, the speed of the PMSM was high and the polar number was large. Limited by the efficiency requirements of the controller and the heat dissipation of power devices, the control switch frequency was small. It can be seen from the simulation that, in the case of low carrier ratio, the motor's own impedance coupling led to a deterioration in current-loop performance. After the addition of angle delay, the coupling effect became more serious, the overshot of the $q$-axis current was larger and the response was slower, and the amplitude of the $d$-axis coupling current was larger. 
Compared with the traditional two decoupling methods, when the angle delay was not considered, it could be seen from the complex-coefficient transfer functions that both methods could decouple the current loop to the first-order system. Therefore, there was no fluctuation of $d$-axis current and the same dynamic performance of $q$-axis current could be seen. However, after the angle delay was added, the complex-coefficient transfer function of the CC-PI decoupling method was simpler. The pole in the right half plane appeared only when the delay angle $\theta_{d}>\pi / 2 \mathrm{rad}$, which meant that the current loop became unstable. On the contrary, the closed-loop pole expression of the CFB decoupling method was very complicated and more parameter-sensitive. Simulation and experimental results showed that the CC-PI decoupling method had better dynamic response characteristics than the CFB decoupling method.

After adopting the proposed ACCC-PI controller, the current loop had a negative real-part closed pole $\left(\omega_{b}, 0\right)$, and the performance of the current loop was only related to the control bandwidth. Compared with the CC-PI and CFB decoupling method, the proposed ACCC-PI decoupling method had the smallest coupling $d$-axis current and the best $q$-axis current dynamic performance. However, due to the change of motor inductance and other parameters, the perfect decoupling effect achieved in simulation could not be realized in the experiment.

\section{Conclusions}

The model of the PMSM and the angle delay model of the digital system, which had similar coupling structures, were established in this paper. The traditional decoupling method only compensated for the impedance coupling term of the PMSM, and did not consider the coupling effect caused by the delay angle. Based on the derivation and analysis of the complex-coefficient transfer functions of the current loop, an angle-compensating, complex-coefficient PI (ACCC-PI) controller was proposed. Using the ACCC-PI controller proposed in this paper, the $q$-axis current response was fast and there was no overshoot. The performance was basically the same as that of the CC-PI decoupling method, and the coupling $d$-axis current amplitude was the minimum. However, due to the changes of motor resistance, inductance and other parameters in the actual system, the $d$-axis coupling current in the experiment was not completely eliminated, and further optimization research on the influence of motor parameters on decoupling performance is still needed.

Author Contributions: Conceptualization, J.G. and T.F.; methodology, J.G.; software, J.G.; validation, J.G., T.F. and Q.L.; formal analysis, J.G.; investigation, J.G.; resources, J.G.; data curation, J.G.; writingoriginal draft preparation, J.G.; writing-review and editing, J.G.; visualization, J.G.; supervision, X.W.; project administration, X.W.; funding acquisition, X.W. All authors have read and agreed to the published version of the manuscript.

Funding: This study was funded by the Strategic Priority Research Program of Chinese Academy of Sciences (grant number XDA28040100).

Data Availability Statement: Not applicable, all research data and results have been given in the paper.

Conflicts of Interest: The authors declare no conflict of interest.

\section{References}

1. Wang, X.; Loh, P.C.; Blaabjerg, F. Stability Analysis and Controller Synthesis for Single-Loop Voltage-Controlled VSIs. IEEE Trans. Power Electron. 2017, 32, 7394-7404. [CrossRef]

2. Bibian, S.; Jin, H. Time delay compensation of digital control for DC switch mode power supplies using prediction techniques. IEEE Trans. Power Electron. 2000, 15, 835-842. [CrossRef]

3. Rahman, M.A.; Milasi, R.M.; Lucas, C. Implementation of emotional controller for interior permanent-magnet synchronous motor drive. IEEE Trans. Ind. Appl. 2008, 44, 1466-1476. [CrossRef]

4. Yim, J.-S.; Sul, S.-K.; Bae, B.-H.; Patel, N.; Hiti, S. Modified Current control schemes for high performance permanent magnet AC drives with low sampling to operation frequency ratio. IEEE Trans. Ind. Appl. 2009, 45, 763-771. [CrossRef] 
5. Shen, J.; Schroder, S.; Stagge, H.; de Doncker, R.W. Precise modeling and analysis of dq-frame current controller for high power conveters with low pulse ratio. In Proceedings of the IEEE Energy Conversion Congress and Exposition ECCE 2012, Raleigh, NC, USA, 15-20 September 2012; pp. 61-68.

6. Qiu, T.; Wen, X.; Zhao, F. Adaptive-Linear-Neuron-Based Dead-Time Effects Compensation Scheme for PMSM Drives. IEEE Trans. Power Electron. 2016, 31, 2530-2538. [CrossRef]

7. Xia, C.; Liu, N.; Zhou, Z.; Yan, Y.; Shi, T. Steady-State Performance Improvement for LQR-Based PMSM Drives. IEEE Trans. Power Electron. 2018, 33, 10622-10632. [CrossRef]

8. Mohamed, Y.A.I. Design and Implementation of a Robust Current-Control Scheme for a PMSM Vector Drive with a Simple Adaptive Disturbance Observer. IEEE Trans. Ind. Electron. 2007, 54, 1981-1988. [CrossRef]

9. Yoon, S.; Oh, H.; Choi, S. Controller Design and Implementation of Indirect Current Control Based Utility-Interactive Inverter System. IEEE Trans. Power Electron. 2013, 28, 26-30. [CrossRef]

10. Bolognani, S.; Oboe, R.; Zigliotto, M. Sensorless full-digital PMSM drive with EKF estimation of speed and rotor position. IEEE Trans. Ind. Electron. 1999, 46, 184-191. [CrossRef]

11. Harnefors, L.; Nee, H.P. Model-based current control of AC machines using the internal model control method. IEEE Trans. Ind. Appl. 1998, 34, 133-141. [CrossRef]

12. Zhang, J.; Meng, Z.; Chen, R.; Sun, C.; An, Y. Decoupling control of PMSM based on exact linearization. In Proceedings of the 2011 International Conference on Electronic \& Mechanical Engineering and Information Technology, Harbin, China, 12-14 August 2011; pp. 1458-1461.

13. Yepes, A.G.; Vidal, A.; López, O.; Doval-Gandoy, J. Evaluation of Techniques for Cross-Coupling Decoupling Between Orthogonal Axes in Double Synchronous Reference Frame Current Control. IEEE Trans. Ind. Electron. 2014, 61, 3527-3531. [CrossRef]

14. Jung, J.; Nam, K. A dynamic decoupling control scheme for high-speed operation of induction motors. IEEE Trans. Ind. Electron. 1999, 46, 100-110. [CrossRef]

15. Xia, X.; Moog, C.H. Disturbance decoupling by measurement feedback for SISO nonlinear systems. IEEE Trans. Autom. Control 1999, 44, 1425-1429. [CrossRef]

16. Xia, C.; Guo, C.; Shi, T. A Neural-Network-Identifier and Fuzzy-Controller-Based Algorithm for Dynamic Decoupling Control of Permanent-Magnet Spherical Motor. IEEE Trans. Ind. Electron. 2010, 57, 2868-2878.

17. Zhou, S.; Liu, J.; Zhou, L.; Zhang, Y. DQ Current Control of Voltage Source Converters with a Decoupling Method Based on Preprocessed Reference Current Feed-forward. IEEE Trans. Power Electron. 2017, 32, 8904-8921. [CrossRef]

18. Vafaie, M.H.; Dehkordi, B.M.; Moallem, P.; Kiyoumarsi, A.; Zhu, Z.Q.; Howe, D. Improving the steady-state and transient-state performances of PMSM through an advanced deadbeat direct torque and flux control system. IEEE Trans. Power Electron. 2017, 9, 2964-2975. [CrossRef]

19. Holtz, J.; Quan, J.; Pontt, J.; Rodriguez, J.; Newman, P.; Miranda, H. Design of fast and robust current regulators for high-power drivers based on complex state variables. IEEE Trans. Ind. Appl. 2004, 40, 1388-1397. [CrossRef]

20. Bahrani, B.; Kenzelmann, S.; Rufer, A. Multivariable-PI-based dq current control of voltage source converters with superior axis decoupling capability. IEEE Trans. Ind. Electron. 2011, 58, 3016-3026. [CrossRef]

21. Ichikawa, S.; Tomita, M.; Doki, S.; Okuma, S. Sensorless Control of Synchronous Reluctance Motors Based on Extended EMF Models Considering Magnetic Saturation With Online Parameter Identification. IEEE Trans. Ind. Appl. 2006, 42, 1264-1274. [CrossRef]

22. Zhao, Y.; Qiao, W.; Wu, L. An Adaptive Quasi-Sliding-Mode Rotor Position Observer-Based Sensorless Control for Interior Permanent Magnet Synchronous Machines. IEEE Trans. Power Electron. 2013, 28, 5618-5629. [CrossRef] 